\title{
MORPHOLOGY OF PHYSIOLOGICALLY IDENTIFIED W-CELLS IN THE C LAMINAE OF THE CAT'S LATERAL GENICULATE NUCLEUS ${ }^{1}$
}

\author{
L. R. STANFORD, MICHAEL J. FRIEDLANDER, ${ }^{2}$ AND S. MURRAY SHERMAN ${ }^{3}$ \\ Department of Neurobiology and Behavior, State University of New York at Stony Brook, Long Island, New York 11794
}

\begin{abstract}
The projections from the retina through the lateral geniculate nucleus to the visual cortex in the cat are comprised of three parallel, independent pathways. These three pathways involve, respectively, W-, X-, and Y-cells in the retina and the lateral geniculate nucleus. In this study, we investigated the morphology of those neurons in the $\mathrm{C}$ laminae of the lateral geniculate nucleus that receive input from retinal W-cells. Micropipettes filled with horseradish peroxidase (HRP) were used to record the responses of single geniculate neurons identified as $\mathrm{W}_{-}, \mathrm{X}-$, or Y-cells. Five $\mathrm{W}$ cells in the $\mathrm{C}$ laminae then were stained intracellularly by impalement of the cell with the microelectrode followed by iontophoresis of HRP. Each of these neurons has a small to medium size soma and fine dendrites oriented roughly parallel to the plane of the geniculate laminar borders. These geniculate W-cells differ among themselves mainly in the detail of their dendritic processes. Three of these cells have virtually no dendritic appendages, while the other two have complex appendages not previously reported among neurons in the $\mathrm{C}$ laminae. Also, the degree of horizontal orientation of the dendrites differs considerably among these cells. Overall, the morphology of these W-cells is generally consistent with the class 4 cell briefly described by Guillery (Guillery, R. W. (1966) J. Comp. Neurol. 128: 21-50), and consequently, our data indicate that class 4 neurons are the morphological correlate of neurons physiologically classified as W-cells. Since greater morphological detail is presented by these HRP-filled cells than by previous Golgi-impregnated preparations, we can describe more completely the morphology of class 4 cells.
\end{abstract}

The aim of this study was to determine directly the morphology of individual $\mathrm{W}$-cells in the $\mathrm{C}$ laminae of the cat's lateral geniculate nucleus. W-cells comprise one of three parallel, independent pathways from the retina through the lateral geniculate nucleus to the visual cortex (Cleland and Levick, 1974; Cleland et al., 1975; Wilson and Stone, 1975; Wilson et al., 1976; Leventhal, 1979; Geisert, 1980; Raczkowski and Rosenquist, 1980). The other two pathways are comprised of $\mathrm{X}$ - and Y-cells (Fnroth-Cugell and Robson, 1966; Hoffmann et al., 1972). In addition to their projection to geniculate $\mathrm{W}$-cells in the $\mathrm{C}$ laminae, retinal $\mathrm{W}$-cells also project to the medial interlaminar nucleus (Dreher and Sefton, 1979), particularly to its rostral thalamic extension (Guillery et al., $1980)$, to the ventral division of the lateral geniculate nucleus (Spear et al., 1977), to the pretectal nucleus of the optic tract (Hoffmann and Schoppmann, 1975), and to the superior colliculus (Hoffmann, 1973).

This research was supported by United States Public Health Service Grant EY 03038. We gratefully thank Sally Gibson and Joan Sommermeyer for their expert technical assistance.

${ }^{2}$ Current address: Department of Physiology and Biophysics, 401 Volker Hall, University of Alabama at Birmingham, Birmingham, AL 35294

${ }^{3}$ To whom correspondence should be addressed.
We have been particularly interested in the question as to whether functional types of neurons possess characteristic morphological features. Recently, Friedlander et al. $(1979,1981)$ used intracellular injection of horseradish peroxidase (HRP) into physiologically identified neurons to show that geniculate $\mathrm{X}$-cells possess morphological features distinct from those of Y-cells. Briefly, Xcells have small to medium size somata with dendrites contained within one lamina and a dendritic tree oriented perpendicular to the laminar borders. Y-cells have larger somata with translaminar dendrites and radially symmetric dendritic arbors. According to the morphological classification scheme of Guillery (1966), the X-cells generally occupy classes 2 and 3 and the Y-cells occupy classes 1 and 2 (Friedlander et al., 1981).

We have begun to use this intracellular HRP approach to study W-cells in the C laminae of the lateral geniculate nucleus. Guillery (1966) has described a population of C laminae neurons, termed class 4 , that have medium size somata and a dendritic tree oriented parallel to the geniculate laminar borders. The data from the present experiments have enabled us to describe the morphology of cells in the cat lateral geniculate nucleus that are physiologically classified as W-cells and, further, to suggest a correlation between physiological W-cells and the 
class 4 morphology. A preliminary report of these results was presented recently (Stanford et al., 1980).

\section{Materials and Methods}

The methods used in these experiments have been described previously, and therefore, only a brief description will be given here. Further details of the physiological preparation, visual stimulation, electrophysiological recording techniques, and histological procedures can be found elsewhere (Friedlander et al., 1979, 1981). Adult cats ( 2 to $4 \mathrm{~kg}$ ) were used for all experiments. All surgical procedures were performed under halothane anesthesia. For the recording session, the halothane was discontinued and the animals were maintained on a mixture of $70 \% \quad \mathrm{~N}_{2} \mathrm{O}$ and $30 \% \quad \mathrm{O}_{2}$ with a continuous infusion of Flaxedil (gallamine triethiodide) at $3.6 \mathrm{mg} / \mathrm{hr}$ and $d$. tubocurarine at $0.7 \mathrm{mg} / \mathrm{hr}$ in a $5 \%$ lactated Ringer's solution.

Bipolar stimulating electrodes were positioned across the optic chiasm to activate the retinal input to geniculate neurons. Also, an array of four electrodes was placed stereotaxically into the optic radiation below the visual cortex to provide antidromic and/or trans-synaptic stimulation of geniculate neurons. Antidromic activation was verified by the spike collision test. Visual stimuli con- sisted of both hand-held targets flashed or moved against a frontal tangent screen as well as counterphased, sine wave gratings generated on a cathode ray tube. The gratings could $b$ ? varied continuously in counterphase rate, spatial fre fuency, spatial phase, and contrast (from 0 to 0.6 ).

Single unit recordings were obtained from the lateral geniculate nucleus with micropipettes filled with 4 to $6 \%$ HRP (Sigma type VI) in a $0.2 \mathrm{M} \mathrm{KCl}, 0.05 \mathrm{~m}$ Tris (tris(hydroxymethyl)aminomethane) buffer solution. The micropipettes were beveled to a final impedance of 80 to 100 megohms at $100 \mathrm{~Hz}$. The neurons encountered in the lateral geniculate nucleus were classified extracellularly on the basis of a battery of tests including: latency of orthodromic response from optic chiasm stimulation, size and responsiveness of receptive field, strength of inhibitory surround (if present), and linearity of spatial summation from responses to the counterphased sine wave gratings (Enroth-Cugell and Robson, 1966; Hochstein and Shapley, 1976; Lehmkuhle et al., 1980). After classification of the neuron, the electrode was advanced in small steps and brief depolarizing current pulses were used to impale the cell. The responses of the neuron were tested again to ensure that the impaled cell was the cell previously classified extracellularly, and the cell was then

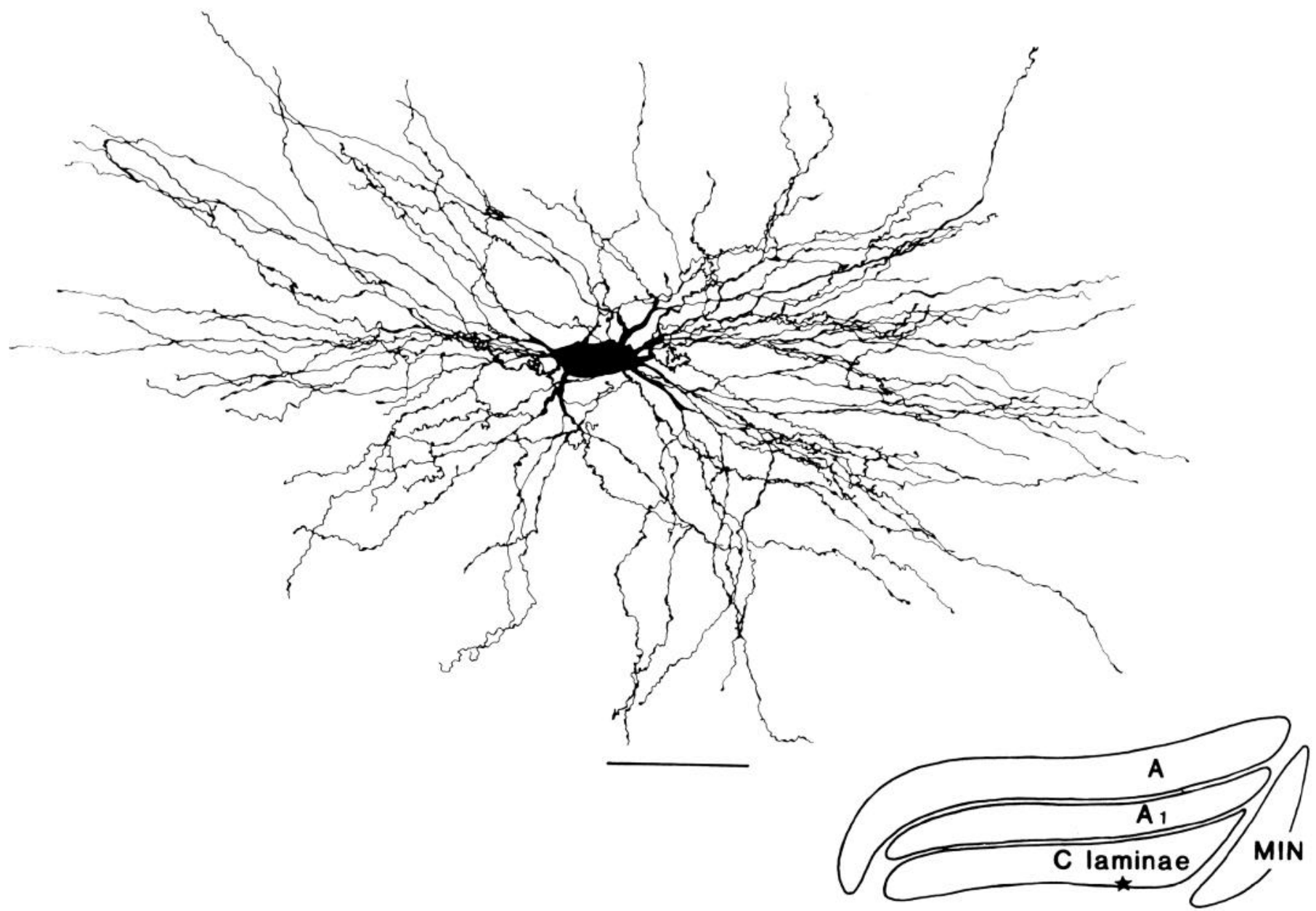

Figure 1. Microscope tracing of a W-cell. The scale is $50 \mu \mathrm{m}$ and applies only to the somatic and dendritic tracings. For reference, the scale is oriented parallel to the laminar borders in the lateral geniculate nucleus. The inset shows the location of the soma of this cell, indicated by the star, near the ventral border of the $\mathrm{C}$ laminae. MIN refers to the medial interlaminar nucleus. 

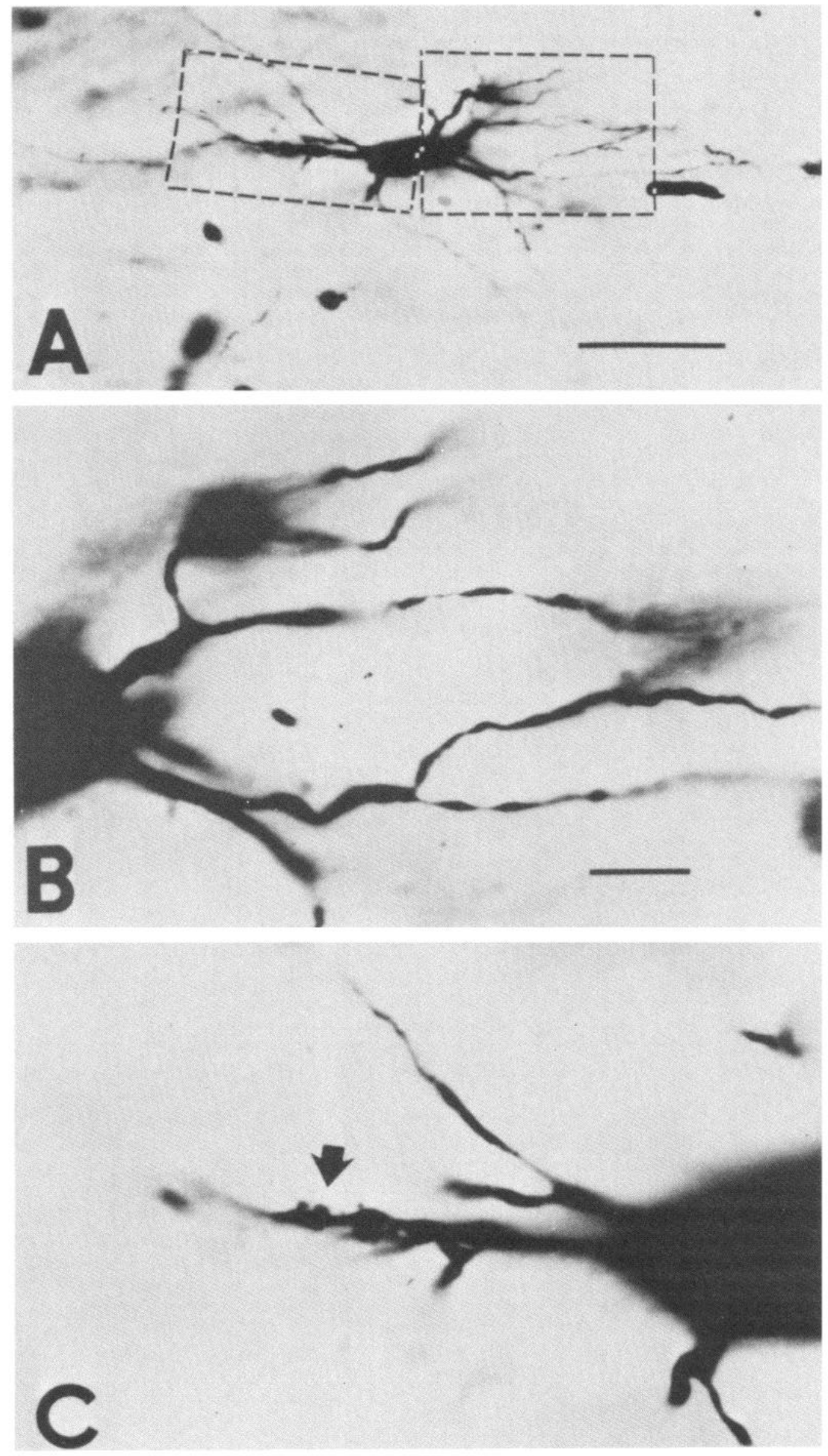
TABLE I

Physiological properties of morphologically identified $W$.cells Responses too poor or sluggish to evaluate are indicated by asterisks.

\begin{tabular}{|c|c|c|c|c|c|c|c|}
\hline $\begin{array}{c}\text { Cell } \\
\text { Illustration }\end{array}$ & $\begin{array}{c}\text { Optic } \\
\text { Chiasm } \\
\text { Latency }\end{array}$ & $\begin{array}{c}\text { Receptive } \\
\text { Field } \\
\text { Center size }\end{array}$ & $\begin{array}{c}\text { Receptive } \\
\text { Field } \\
\text { Eccentricity }\end{array}$ & $\begin{array}{c}\text { Ocular } \\
\text { Dominance } \\
\text { (Eye) }\end{array}$ & $\begin{array}{l}\text { Center } \\
\text { Type }\end{array}$ & $\begin{array}{l}\text { Phasic or } \\
\text { Tonic }\end{array}$ & $\begin{array}{l}\text { Linear or } \\
\text { Nonlinear }\end{array}$ \\
\hline \multicolumn{8}{|c|}{ msec } \\
\hline Figure 1 & 4.5 & $1.5^{\circ}$ & $3.5^{\circ}$ & Contralateral & On & Phasic & Linear \\
\hline Figure $3 A$ & 2.5 & $1.0^{\circ}$ & $4.5^{\circ}$ & Contralateral & On & Phasic & $*$ \\
\hline Figure $3 B$ & 5.0 & $*$ & $2.0^{\circ}$ & • & $*$ & * & $*$ \\
\hline Figure $3 C$ & 5.5 & $*$ & $1.0^{\circ}$ & Ipsilateral & On & Phasic & $*$ \\
\hline Figure $3 D$ & 4.0 & $0.5^{\circ}$ & $3.0^{\circ}$ & Contralateral & On & Tonic & Linear \\
\hline
\end{tabular}

injected iontophoretically with HRP. For iontophoretic injection, we used depolarizing current pulses of 1 to 10 $\mathrm{nA}$ at 3 to $4 \mathrm{~Hz}$ with a pulse duration of 100 to $200 \mathrm{msec}$.

Since we wished to inject only W-cells in these experiments, we limited our injections to neurons in the $\mathrm{C}$ laminae of the lateral geniculate nucleus. These laminae contain a large population of W-cells (Wilson et al., 1976). We inferred electrode penetration of lamina $\mathrm{C}$ by a predictable progression of ocular dominance shifts as the electrode advanced through the geniculate laminae. That is, the first visual neurons were excited by stimulation of the contralateral eye and indicated penetration of lamina $\mathrm{A}$; when fields shifted to the ipsilateral eye, the electrode presumably reached lamina $\mathrm{A} 1$; and a shift back to the contralateral eye indicated penetration of lamina C. Every recovered cell presumed to be in the $\mathrm{C}$ laminae by these criteria was, in fact, located there.

A cell was classified as a W-cell if it responded to electrical stimulation of the optic chiasm with a latency of $>2.5$ msec and responded "sluggishly" to visual stimulation of its receptive field (Cleland et al., 1975). A sluggish response has been defined as one in which a low peak firing rate is evoked by stimulation (Cleland and Levick, 1974). Although this might seem a somewhat subjective determination, since we did not quantitatively measure firing rates, the responsiveness of these $\mathrm{W}$-cells was qualitatively quite different from the "brisker" responses of X- and Y-cells. Furthermore, we noted that, when compared to X-and Y-cells, these W-cells have markedly poor contrast sensitivity to counterphased sine wave gratings, and indeed, some $\mathrm{W}$-cells failed to respond to gratings of any spatial and temporal frequency, even at maximum (0.6) contrast (a detailed report of this is being prepared). No X- or Y-cell ever failed to respond to such stimuli.

At the end of the recording session, the animal was given a large intravenous dose of barbiturate and perfused transcardially with a mixture of $1 \%$ paraformaldehyde and $2 \%$ glutaraldehyde in $0.1 \mathrm{~m}$ phosphate buffer at $\mathrm{pH}$ 7.4. A block of tissue containing the lateral geniculate nucleus then was removed stereotaxically. The tissue was postfixed for 4 to $12 \mathrm{hr}$, washed in phosphate buffer overnight, cut on a Vibratome in the coronal plane at a thickness of $100 \mu \mathrm{m}$, and reacted with $3,3^{\prime}$-diaminobenzidine.

Sanderson's (1971) maps of the retinotopic projection onto the lateral geniculate nucleus were used to correlate each recovered neuron with the receptive field of an HRP-injected cell. No more than three W-cells, at widely spaced locations, were injected in any cat. The visual responses of some $\mathrm{W}$-cells were so inconsistent that it was difficult to estimate reliably their receptive field borders. For this reason, the receptive fields of X- and Ycells encountered in the A laminae were plotted carefully in each electrode penetration. This procedure allowed us to identify recovered W-cells whose receptive fields could not be mapped reliably.

The injected neurons were traced using a drawing tube attached to a microscope with a $\times 100$ oil objective (numerical aperture, 1.32). Each cell was reconstructed from several sequential sections. A Kodak Wratten 48A filter was used to enhance the contrast between the background and the HRP reaction product.

\section{Results}

Five neurons, physiologically classified as W-cells and located in the $\mathrm{C}$ laminae, have been injected successfully with HRP and recovered. All of these cells were confirmed as relay cells because of the presence of axons that could be traced well into the optic radiations, and one of the cells was also antidromically activated from cortex. We were unable to obtain antidromic activation from cortex of any of the remaining four W-cells despite the presence of an axon in the optic radiations for each of them. Possible reasons for this failure to achieve such antidromic activation of relay cells is discussed in a separate report (Friedlander et al., 1981).

Each of the five W-cells responded sluggishly to visual stimuli (see "Materials and Methods"). Table I shows additional physiological properties of these cells, including: the latency to optic chiasm stimulation, eccentricity of the receptive field from the area centralis, whether the receptive field borders could be reliably plotted (the eccentricity values for poorly responsive fields were often

Figure 2. Photomicrographs of the W-cell drawn in Figure 1. A, Lower power view of the W-cell. The dashed rectangles outline higher power views in $B$ and $C$. The scale is $50 \mu \mathrm{m}$ and is oriented parallel to the laminae. $B$, Higher power view of region indicated by right rectangle in $A$. The scale is $10 \mu \mathrm{m}$ and also applies to $C$. $C$, Higher power view of region indicated by left rectangle in $A$. Note the collection of bulbous structures appended at a dendritic branch point (arrow). 
extrapolated from field positions of nearby neurons; see "Materials and Methods"), ocular dominance, center type (on or off), tonic or phasic responsiveness, and linearity of spatial summation. An asterisk indicates that the cell's responsiveness was too poor or sluggish to evaluate the feature in question. Only one W-cell in
Table I had a latency to optic chiasm stimulation (2.5 msec) sufficiently short to overlap with the most slowly conducting retinal X-cell axons. However, this W-cell failed to respond to the grating stimuli, and every $\mathrm{X}$-cell tested clearly responded to such stimuli. The only W-cell in Table I that could be driven from cortex antidromically

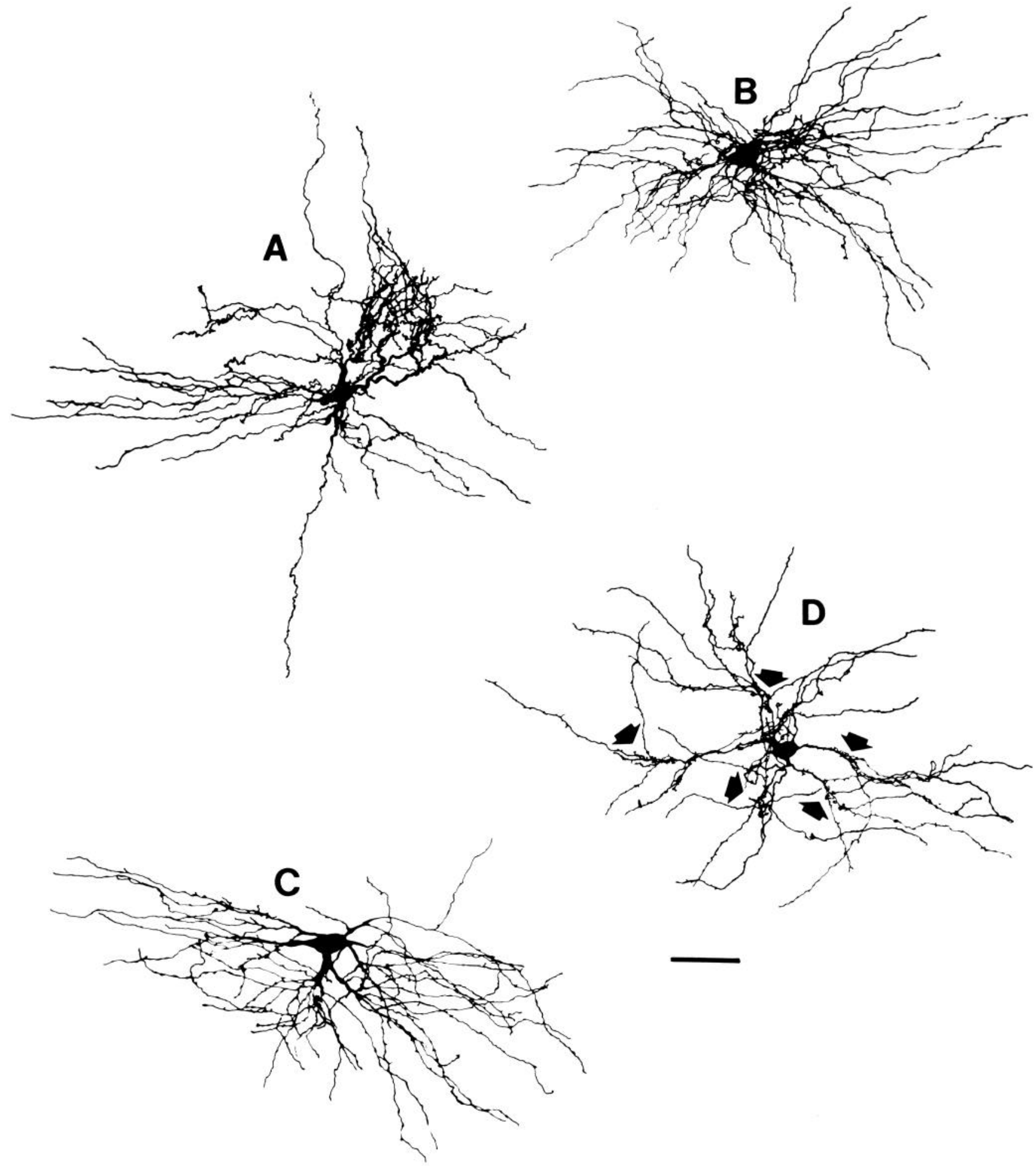

Figure 3. Microscope tracings of the other four W-cells not shown in Figures 1 and 2 . The scale below $D$ applies to all of the cells, is $50 \mu \mathrm{m}$, and is oriented parallel to the laminae. $A$ to $C$, Cells with virtually no dendritic appendages; $D$, cell with numerous appendages clustered near dendritic branch points (e.g., arrows). 
was the cell illustrated in Figure $3 D$, and it had a latency to such stimulation of 3.5 msec. Naturally, we studied many more W-cells electrophysiologically than the five indicated in Table I, since these represent only the small subgroup for which anatomical data are available. Among these W-cells not illustrated are off-center cells, cells with "on-off" responses, and cells with nonlinear spatial summation.

Figure 1 is a microscope tracing of a W-cell and Figure 2 includes photomicrographs of the same neuron. The soma of this W-cell is just dorsal to the border of the lateral geniculate nucleus with the optic tract and has a cross-sectional area of $262 \mu \mathrm{m}^{2}$ (Figs. 1 and $2 A$ ). It is conspicuously flattened in a plane parallel to the geniculate laminae. The rich dendritic arbor of this neuron was reconstructed from five $100-\mu \mathrm{m}$ serial sections. Note that the dendrites are oriented parallel to the laminae, and indeed, the dendritic arbor of this W-cell is the most oriented of the five W-cells. This horizontal dendritic orientation is one primary characteristic of the class 4 neurons described by Guillery (1966). Figure 2, $B$ and $C$, shows the dendrites of this cell in more detail. Although few appendages can be seen, they tend to be concentrated near dendritic branch points in a manner reminiscent of the class 2 cells described by Guillery (1966) for the A laminae. An example is shown in Figure $2 C$.

The axon of this W-cell is extremely thin $(<1 \mu \mathrm{m}$ in diameter). Along its course through the perigeniculate nucleus (immediately dorsal to the lateral geniculate nucleus), this axon contributes very fine collateral branches $(<0.5 \mu \mathrm{m}$ in diameter $)$ ending in terminal swellings. No collaterals from this axon were seen within the lateral geniculate nucleus. We found no collateral branches from axons of the other four W-cells.

All of the five W-cells of this study possess medium size somata (mean, $210 \mu \mathrm{m}^{2}$; range, 165 to $262 \mu \mathrm{m}^{2}$ ) and dendritic arbors oriented more or less parallel to the lamination. These characteristics are consistent with their classification as class 4 neurons. The five $\mathrm{W}$-cells differ from each other primarily in the details of their dendritic morphology, such as the relative thickness and the number of dendrites, the number and appearance of the dendritic appendages, and the degree of orientation of the dendritic arbor.

Three of the W-cells (Fig. 3, $A$ to $C$ ) possess virtually no dendritic appendages. The cell shown in Figure $3 D$ has relatively few dendrites, but appendages are seen at many of the dendritic branch points (arrows). Thus, two of these W-cells have this morphological feature in common with class 2 cells (see also Fig. $2 C$ ).

Figure 4 illustrates the variability in the degree of dendritic orientation by means of a Sholl ring analysis described in detail by Friedlander et al. (1981). Briefly, a series of five concentric circles spaced $50 \mu \mathrm{m}$ apart was drawn onto the tracing of each cell and centered upon the soma. These circles were divided into horizontal and vertical quadrants relative to the laminar borders, and the number of intersections made between the dendrites and rings was counted for each quadrant. Figure 4 shows this analysis along with a line with a slope of 1 to indicate the locus of points expected for radially symmetric dendritic arbors. Each of the W-cells falls below this line,

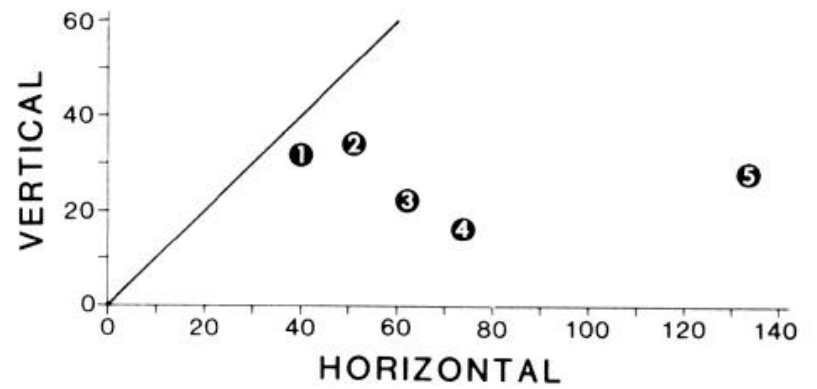

Figure 4. Analysis of dendritic arbors. For each W-cell, five concentric rings, centered upon the soma and spaced $50 \mu \mathrm{m}$ apart, were placed over the microscope tracing. The number of intersections made by these rings and the dendrites then were counted for the two vertical and two horizontal quadrants relative to the laminar orientation (cf., Friedlander et al., 1981). These values are plotted for each cell. For comparison, the line with a slope of 1 is drawn, and this represents the locus of points expected for a dendritic tree with radial symmetry. Each W-cell point falls below this line, thereby indicating a horizontal bias to the dendritic arbor. The numbers refer to the drawings in Figures 1 and 3 as follows: Figure 1, 5; Figure $3 A$, 2; Figure $3 B, 4$; Figure $3 C, 3$; Figure $3 D, 1$. Note the range in this horizontal bias from very little for 1 to considerable for 5 .

suggesting horizontally oriented dendrites. However, the degree of this orientation varies considerably from cell to cell.

\section{Discussion}

Guillery (1966) described a population of neurons in the $\mathrm{C}$ laminae of the cat's lateral geniculate nucleus that have medium sized somata and dendritic arbors oriented parallel to the laminar borders. This represents the morphological class 4 cell. Electrophysiological recordings in the $\mathrm{C}$ laminae have demonstrated that many of the neurons in these laminae belong to a physiological class that receives input from retinal ganglion cells with slowly conducting axons. These geniculate neurons have been termed W-cells (Wilson and Stone, 1975; Cleland et al., 1975; Wilson et al., 1976). The data presented here for the lateral geniculate nucleus indicate that the physiologically identified W-cells are, morphologically, class 4 neurons.

If $\mathrm{W}$-cells are to be associated with class 4 morphology, then the morphological description of this class should be broadened to include the variation described here, including the appearance in some cells of dendritic appendages at branch points. This feature should not be considered a characteristic unique to class 2 cells. Furthermore, we now can associate this morphological feature with some examples of each of the physiological classes, since some X-and Y-cells also possess such appendages at branch points (Friedlander et al., 1981). Thus, there is no reason to believe that such appendages at dendritic branch points are unique to either a morphological class (class 1, 2, 3, or 4) or a physiological class (W-, X-, or Y-cell) of geniculate neurons.

An important qualification to the above conclusion must be emphasized. We have more or less defined class 4 morphology as isomorphic with W-cell physiology. While this is not inconsistent with Guillery's (1966) brief description of class 4 features, our definition includes 
structural details, such as dendritic appendages, and variability not described before. Our restatement of class 4 morphology is thus somewhat arbitrary. One could argue from Guillery's (1966) classification scheme that these C laminae neurons with dendritic appendages at branch points are norphologically class 2 , and thus, class 2 neurons include some $\mathrm{W}$-cells in the $\mathrm{C}$ laminae as well as some $\mathrm{X}$ - and $\mathrm{Y}$-cells in the A laminae (Friedlander et al., 1981). However, we are less concerned with the determination of how these cells distribute among previously defined morphological classes than with a description of the distinctive morphological features of $W_{-}, X_{-}$, and $Y$ cells. We conclude that each of these physiological classes possess morphological features quite distinct from the others, regardless of its position among Guillery's (1966) morphological scheme.

The conclusion that $W$-cells are class 4 is perhaps not surprising since previous reports have established the concentration of these physiological (Wilson et al., 1976) and morphological (Guillery, 1966) classes in the C laminae. Nonetheless, the prior description (Guillery, 1966) of these cells was quite limited due to the difficulty of impregnating neurons in the $\mathrm{C}$ laminae by various Golgi methods. We thus can offer a considerably more detailed morphological description of somatic and dendritic features as well as axonal distributions for these cells. Also, given the capriciousness and difficulty of the Golgi method, it seemed quite possible that previously undiscovered morphological types exist in the $C$ laminae and that many, most, or all W-cells exhibit such morphology. However, we found no evidence for previously unrecognized morphological classes of cells in the $\mathrm{C}$ laminae. Our direct relationship of $W$-cell physiology with class 4 morphology, if unsurprising, is nonetheless useful.

W-cells in the lateral geniculate nucleus, like their retinal counterparts, are a diverse physiological group in terms of their responses to visual stimulation. However, although all of the geniculate $W$-cells recovered thus far are consistent in some morphological features (soma size and general orientation of dendritic arbors), cells in this physiological class may differ widely in the detail of certain dendritic morphological characteristics. An interesting question raised by these data concerns the possible correlations among some of the morphological and physiological variations. Finally, the precise relationship between $W$-cell dendrites and the specific $C$ laminae is unclear from our current data, since we have not used special techniques, such as autoradiographic demonstration of these laminae (Hendrickson, 1969; Cowan et al., 1972), to determine such relationships. Experiments are underway to explore some of these questions regarding the structure/function relationships of $\mathrm{W}$-cells.

\section{References}

Cleland, B. G., and W. R. Levick (1974) Brisk and sluggish concentrically organized ganglion cells in the cat's retina. J. Physiol. (Lond.) 240: 421-456.

Cleland, B. G., R. Morstyn, G. H. Wagner, and W. R. Levick (1975) Long latency retinal input to lateral geniculate neurons of the cat. Brain Res. 91: 306-310.

Cowan, W. M., D. I. Gottlieb, A. E. Hendrickson, J. L. Price, and T. A. Woolsey (1972) The autoradiographic demonstra- tion of axonal connections in the central nervous system. Brain Res. 37: 21-51.

Dreher, B., and J. Sefton (1979) Properties of neurons in the cat's lateral geniculate nucleus: A comparison between medial interlaminar and laminated parts of the nucleus. J. Comp. Neurol. 183: 47-64.

Enroth-Cugell, C., and J. Robson (1966) The contrast sensitivity of retinal ganglion cells of the cat. J. Physiol. (Lond.) 187: 517-522.

Friedlander, M. J., C. -S. Lin, and S. M. Sherman (1979) Structure of physiologically identified X-and Y-cells in the cat's lateral geniculate nucleus. Science 204: 1114-1117.

Friedlander, M. J., C. -S. Lin, L. R. Stanford, and S. M. Sherman (1981) Morphology of functionally identified neurons in the lateral geniculate nucleus of the cat. J. Neurophysiol. 46: in press.

Geisert, E. E. (1980) Cortical projections of the lateral geniculate nucleus of the cat. J. Comp. Neurol. 190: 793-812.

Guillery, R. W. (1966) A study of Golgi preparations from the dorsal lateral geniculate nucleus of the cat. J. Comp. Neurol. 128: 21-50.

Guillery, R. W., E. E. Giesert, E. H. Polley, and C. A. Mason (1980) An analysis of the retinal afferents to the cat's medial interlaminar nucleus and to its rostral thalamic extension. J. Comp. Neurol. 194: 117-142.

Hendrickson, A. (1969) Electron microscopic autoradiography: Identification of origin of synaptic terminals in normal nervous tissue. Science 165: 194-196.

Hochstein, S., and R. M. Shapley (1976) Quantitative analysis of retinal ganglion cell classification. J. Physiol. (Lond.) 262: 237-264.

Hoffmann, K. -P. (1973) Conduction velocity in pathways from retina to superior colliculus in the cat: A correlation with receptive field properties. J. Neurophysiol. 36: 409-424.

Hoffmann, K. -P., and A. Schoppmann (1975) Retinal input to direction selective cells in the nucleus tractus opticus of the cat. Brain Res. 99: 359-366.

Hoffmann, K. -P., J. Stone, and S. M. Sherman (1972) Relay of receptive-field properties in dorsal lateral geniculate nucleus of the cat. J. Neurophysiol. 35: 518-531.

Lehmkuhle, S., K. E. Kratz, S. C. Mangel, and S. M. Sherman (1980) Spatial and temporal sensitivity of X-and Y-cells in the dorsal lateral geniculate nucleus of the cat. J. Neurophysiol. 43: 520-541.

Leventhal, A. G. (1979) Evidence that the different classes of relay cells of the cat's lateral geniculate nucleus terminate in different layers of the striate cortex. Exp. Brain Res. 37: 349372 .

Raczkowski, D., and A. C. Rosenquist (1980) Connections of the parvocellular $\mathrm{C}$ laminae of the dorsal lateral geniculate nucleus with the visual cortex in the cat. Brain Res. 199: 447451.

Sanderson, K. J. (1971) The projection of the visual field to the lateral geniculate and medial interlaminar nuclei in the cat. J. Comp. Neurol. 143: 101-118.

Spear, P. D., D. C. Smith, and L. Williams (1977) Visual receptive field properties of single neurons in the cat's ventral lateral geniculate nucleus. J. Neurophysiol. 40:390-409.

Stanford, L. R., M. J. Friedlander, and S. M. Sherman (1980) Morphology of physiologically identified neurons in the $\mathrm{C}$ laminae of the cat's lateral geniculate nucleus. Soc. Neurosci. Abstr. 6: 583 .

Wilson, P. D., and J. Stone (1975) Evidence of W-cell input to the cat's visual cortex via the C-laminae of the lateral geniculate nucleus. Brain Res. 92: 472-478.

Wilson, P. D., M. H. Rowe, and J. Stone (1976) Properties of relay cells in the cat's lateral geniculate nucleus: A comparison of W-cells with X- and Y-cells. J. Neurophysiol. 39: 11931209. 